\title{
Innovative Approaches In The Education And Development Of Preschool Children
}

\section{Gauhar Djanpeisova ${ }^{1}$ Zarafshan Kalendarova $^{2}$ Asal Urazalieva $^{3}$ Kamola Akbarova ${ }^{4}$ Dono Marasulova ${ }^{5}$}

\author{
${ }^{1}$ head of Chair of Methods of Preschool Education, Tashkent State Pedagogical University named after Nizami, \\ associate professor \\ ${ }^{2}$ Lecturer of Chair of Methods of Preschool Education, Tashkent State Pedagogical University named after \\ Nizami \\ PhD student 2 year of study of the Tashkent State Pedagogical University named after Nizami \\ ${ }^{4}$ Lecturer of Chair of Methods of Preschool Education, Tashkent State Pedagogical University named after \\ Nizami \\ ${ }^{5}$ Lecturer of Chair of Methods of Preschool Education, Tashkent State Pedagogical University named after \\ Nizami
}

\begin{abstract}
:
The content of a scientific article focused on developing in modern corresponding modern model of education and training of views on the development of mathematical concepts and abilities of children development of principles of section and design of the content of mathematical education of preschool children.

Keywords: teaching and development of children;mathematical representations, innovative technologies;logical
\end{abstract} thinking;spatial orientation;game approaches.

Article Received: 16th October, 2020; Article Revised: 30th December, 2020; Article Accepted: 08th January, 2021

\section{Introduction}

Modern educators have great opportunities to construct author programs on mathematical development of a child, which, however, is impossible without a thorough knowledge of the fundamentals and techniques of mathematic theory that is asked by current programs for preschool educational establishments and primary schools and referring to successful experienced traditional, alternative and various approaches to the mathematical training of children.

These trends contribute to the deepening of teaching formation of mathematical concepts in children; they are valid sources for scientific correction of program requirements for the content of mathematics given successive both between kindergarten and primary school; they have interesting ideas that facilitate the process of mathematical development of the child in a family environment[1].

Intellectual activity, based on active search of action modes, in the pre - school age can be habitual and of course, natural, if the efforts of teachers and parents directed to the education of the feeling self interest to the study process, independent search for solutions and to achieve required goal in a child.

\section{The main results and findings "Pentamino"} The essence of the game

From several parts of small squares combinations of a rectangle area it is necessary to form a certain shape without overlaps. 
The sequence of tasks

1. The tasks of familiarizing with a set of shapes for the game with the help of flannel board; finding similarities of "Pentamino" shapes with subject images, for example the letter T, G, C, Z, angle, cross bar, ladder, step, rifle, gun, duck.

2. The tasks of modeling shapes from several parts of the game dissected by imposing models.

3. Placing the pieces in a box according to the scheme.

As a result, the children improve their skills of tactile - moving research of shapes, develop fine motor skills, can master the concepts of "area of a rectangle", "single square", "and equal size shapes". The game "Pentamino" promotes children figurative imagination development.

The teacher' help should be correct, carried out by indirect methods:

- Fixing the child's attention to the lines direction on the sample, the ratio of their length;

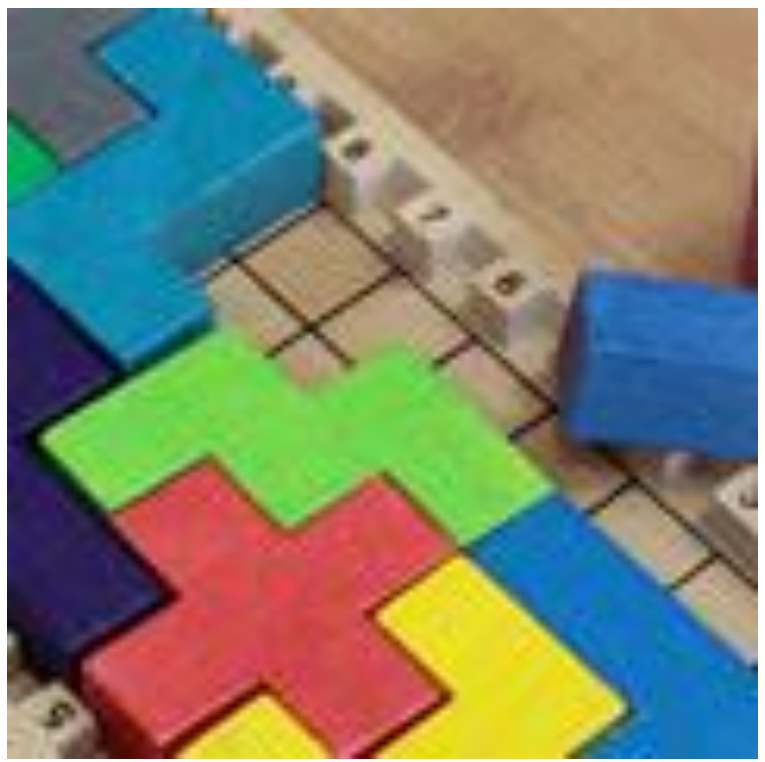

- Joining mind division of conceived shape into its component parts. If necessary, showing the symbol locations of some parts at the sample contour;

- Stimulating creative expressions, desires to model new tasks, etc.

So the game task of simulation on the basis of "Pentamino" material is forming

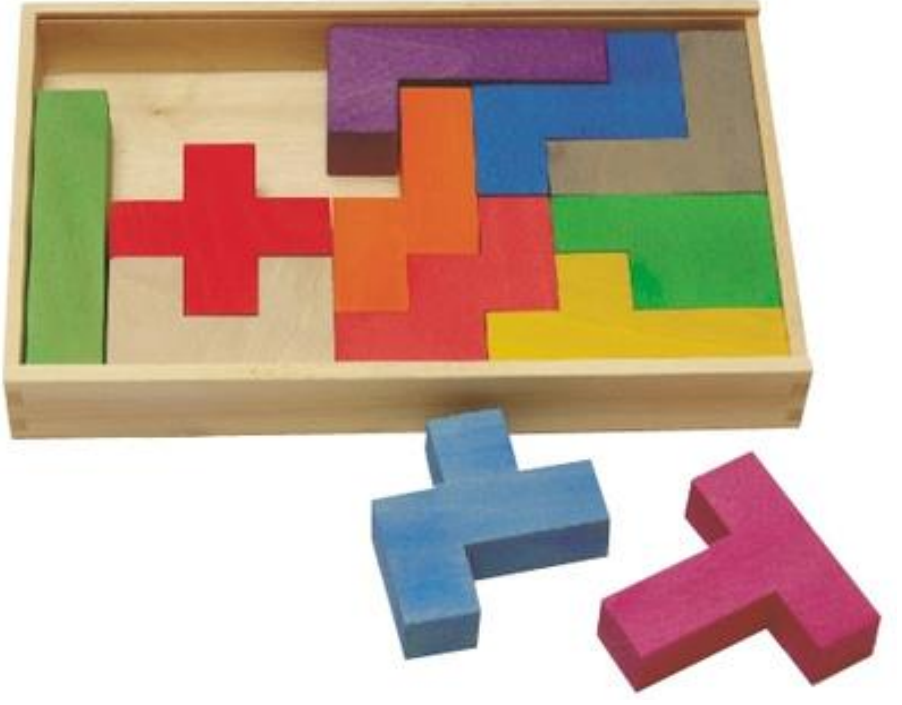

the shape according to the given silhouette; technological stages of modeling familiaritywith the shapes and the search for their substantive counterparts, forming the shapes of increasing complexity level on disjointed schemes (by overlaying and without it), forming the shapes of increasing complexity level on undifferentiated (encircle) schemes, creative design of new silhouettes.

For modeling the electronic version of "Pentamino" may also be used, in which detailed scheme of mathematical modeling is used:

- Choosing the shape-silhouettes of various degrees of complexity from the database;

- Heuristic compilation of selected pieces of undifferentiated scheme in view of the possible combinatorial variations and the time factor;

- Construction of new shapes for modeling with the ability to make successful models in the database and automatically assessment and their degree of complexity. The electronic version of the planar mathematical modeling is highlighted with dynamism, dialogue, clarity, provides individual attention to participants in the process of modeling, stimulate their intellectual activeness, and improve their usage skills.

\section{The stages of simulation}


1. Familiarity with the material: usually done when the child has already known the colors well, so before you give him the materials of games, make a beautiful pattern and place it with cubes directly into the box; opening the box for the first time, a child fall in love with design.

2. Simulation on color dissected schemes of predetermined patterns by imposing

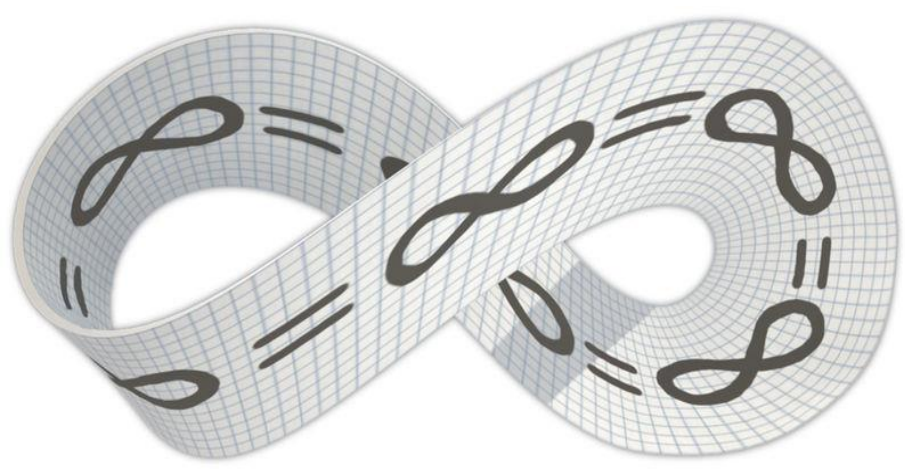

methods of 4 blocks; without imposing from 4 blocks, then from 9 and from 16 cubes; modeling patterns of 4 blocks on color undivided schemes.

3. Simulation of color patterns of 9 blocks, then 16 blocks of undivided schemes in order of increasing complexity level.

4. Simulation of color patterns of 16 blocks of undivided schemes taking into account the speed factor; perform reverse tasks (looking at the blocks, draw a pattern that they form) using square stencil; modeling of new tasks from different number of blocks.

Modeling technologies on planar materials, causing a keen interest in children, develop their analytical and synthetic, creative abilities, visual memory, imagination, fine motor skills.

\section{Spatial modeling on the basis of cutting rectangular parallelepiped}

There is a predetermined rectangular parallelepiped (cuboids). The simplest three - dimensional shapes, to which can be cut to obtain materials for the simulation are the cube and cuboids (rectangular parallelepiped). Suppose that the partition is made, if all the parts are equivalent to the selected partition, the resulting set does not contain equivalent classes.

\section{The essence of the game}

To build a model from blocks according to the drawings-tasks.

\section{Preparation to the game}

You should make 8 similar wood blocks with a ratio of 1:2:4. Nowadays there are widely used ready sets from hollow plastic; in self - making it should be paid attention to the fact that the borders of brick must be mutually perpendicular. A box is needed for bricks.

The set of bricks should be in every child. After making bricks on separate sheets of construction paper you should prepare drawings - tasks.

\section{"Mobius strip"}

According to the current program requirements, even senior preschoolers can easily distinguish between simple planar shapes and spatial shapes, they even know what the internal and external surface of the shape is. To simulate Mobius strip under the guidance of the teacher is not very difficult task for children. In this case, it is important to organize the process of modeling so that children can understand the characteristics of the Mobius strip as a one - sided surface.

\section{Simulation}

\section{Stage 1.Problem formulation}

Educator. Let's try to answer the question: whether all the items are bilateral?

To understand the essence of the question

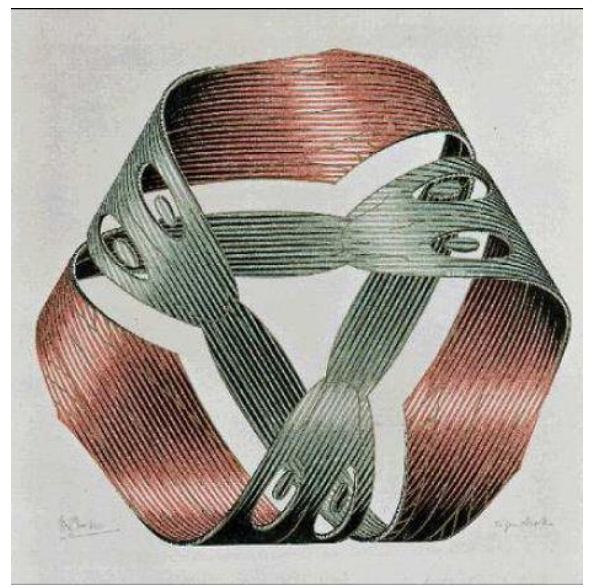


teacher offers to take an experiment.

Take a box without top cover, lid

In one of the side walls make a pinhole. Imagine that inside the box at the pinhole there is sitting a spider and outside at the same pinhole is an ant.

The ant wants to go on a visit to his friend. Through a pinhole in the wall it cannot crawl, therefore it crawls by passing the creeps. No matter how it crawls, it will have to get over the edge of the box. If the edge will be covered with Velcro, the ant did not reach the goal. Why is that?

Children. Because the bow has two sides.

Educator. Give examples of other bilateral surfaces.

Children. Glass (cylinder), a closed box (cube), brick (parallelepiped), the ball (sphere).

Educator. Before us is a problem - if there is a figure, shape, which has only one surface?

\section{Stage2.Reproductive modeling}

The children have on their table in front of them the glue, a brush and two similar strips of graph paper, each of which applied to the middle line with felt tip pen. Under the guidance of a teacher from one strip they simulate a "ring" - a cylindrical tape; from another - a Mobius strip, for which strip is twisted near one of the ends of the half - turn, and its ends are stuck together.

Teacher repeatedly utters the name of the new geometrical shape frontally. Then, help children firmly glue the ends of the strips, individually repeating the name of a new shape.

\section{Stage 3. Researching game}

The teacher offers to play with the "ring" and Mobius strip.

Educator. Note any point on the dotted line of cylindrical tape. Imagine that an ant sits here; on the other side there is a spider.

The ant cannot crawl through the hole. How did it get to the spider? Can the ant get to the spider, without going over the edge of the tape?

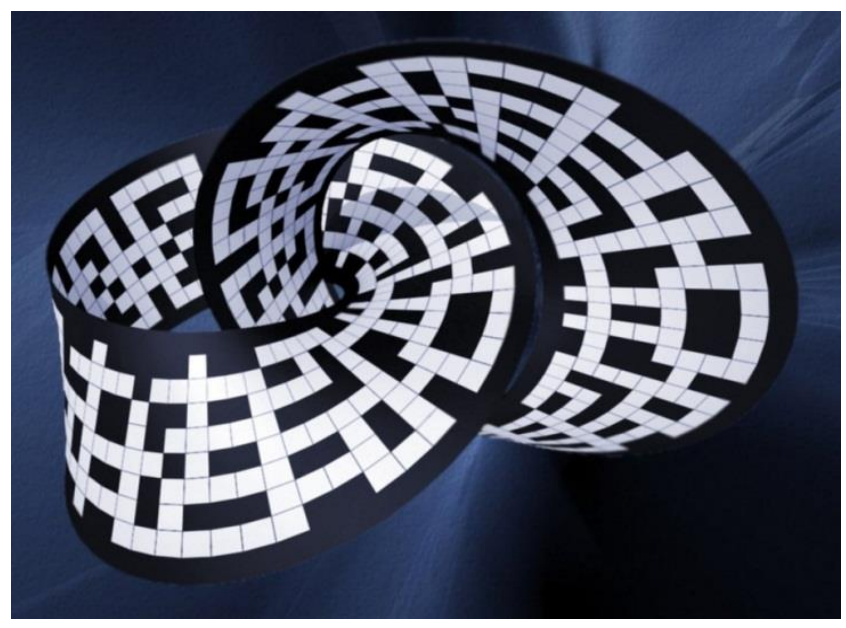

Children. No.

Educator. Why is that?

Children. This tape has two sides and two ends.

Educator. Now take a Mobius strip and play the same game. At one point an ant is sitting, on the other - the spider. The ant gets to his friend if it crawls over the edge. But if it moves on the dotted line, it also gets to the spider! This is possible because the Mobius strip has magical property - it is one - sided!

Let's play another interesting game "Write a letter". Imagine that we are going to write a letter in a fairy language.

We cannot take the pencil up from the paper. You cannot cross over the edge. Try, will you be able to fill both sides of the "ring"?

Children. No, because it has two sides.

Educator. And if we write a fairy letter on the Mobius strip? Remember, we cannot take the pencil from the paper, it is impossible to pass over the edge. Whether the Mobius strip is entirely written? Try.

Children. Yes, because it is one - sided.

\section{Stage 4. Practical researching modeling task}

1. Make an incision in the midline of that shape, which is obtained by first cutting of a Mobius strip, what happens?

2. Draw and cut out paper soldier; send it to travel along a line, running in the 
middle of a Mobius strip, in what image will it return to the starting point?

3. And this task for future inventors! Gear belt of a sewing machine is put on the two pulleys. When you rotate one side of the belt touches pulleys surfaces, as for the other - no touching; as a result, the first side wears out and the belt begins to slip.

Suggest a way allowing to us prolong the life of the belt.

In today's kindergarten, then in school children get acquainted with Euclidean geometry, where all valid conversions mainly consist of movements (shifting shapes) mirror reflections (axial symmetry), compression, stretching (similarity).

The top of this approach is the study of the theory of sets, when the shape is allowed to "scatter" on certain points, to form out a new shape from them.

According to Swiss psychologist Jean Piaget, children perceive the geometric properties in reverse order, i.e., it is easier to understand to the baby the difference between small groups of red and blue balls or cubes (set theory), or between a closed and an open in - ring rubber ribbon (topology) than to distinguish rectangular from hexagon (Euclidean geometry). Therefore getting acquainted with a Mobius strip from certain positions completely corresponds to children's nature.

The proposed technology is economical (modeling material is simple and accessible), dynamic (performed in 1- 2 lessons), a new one (provides preschoolers qualitatively development of new class of geometric shapes - one - sided surfaces), based on a wide range of methods and provides frontal variant of realization.

\section{Conclusion}

It should be remembered that the content of activities on mathematical development of the child in any approach must be consistent with its age features and requirements for training, providing further development; consider the possibilities of modern information technologies; provide ways to adjust.

Forms and methods of work are determined by the necessity of realization of humanistic ideas of understanding world through games and a harmonious fusion of social and family education that is provided by self - oriented cooperation of adults with children in the process of organization of children's activities.

Presented direction define following position to teachers, i.e. suggest the possibility of selecting children's own ways of solving educational problems and following on it in accordance with its own characteristics, leading to keep unique, multi - level and diversity of preschoolers within mathematics as a field of knowledge.

This setting directs teachers to the development of a deep scientific mathematic foundation of theory of sets, the use of unobtrusive methods and techniques that provide the efficiency of formation mathematic representations in all subjects involved in this process.

\section{References:}

[1] Childraft-The flow and Why Library. Mathemagie. (Reg. U.S. Pat and T.M. Off Marca Registrada). Chicago, World Book Inc., 2008. $288 \mathrm{p}$.

[2] Djanpeisova G.E. Modern aspects of mathematics education of preschool children. / Methodical aid. T.: TSPU named after Nizami, 2017. - $106 \mathrm{p}$.

[3] Jumaev M. Theory and methods of development of basic mathematical concepts in children. / Textbook for pedagogical professional colleges. T.: Ilm-Ziyo, 2013.

[4] Kumon Publishing. Geometry \& Measurement Grade 1 PDFMath Workbook, Kumon Publishing, 2008 USA, $-80 \mathrm{p}$.

[5] Mathematics in Early Childhood and Primary Education (3-8 years). Definitions, Theories, Development 
and Progression. By Professor Bob Perry. Charles Sturt University, Australia. 2014. Educational Research Centre - 166 p.

[6] Peter Sullivan. Teaching Mathematics: Using researchinformed strategies. Australian Council for Educational Research. Australia. 2011. By ACER Press $80 \mathrm{p}$.

[7] Suzanne Lowell Krogh. Educating young children. Infancy to Grade Three Western Washington University. - 2004. By McGraw Hill, Inc, $-561 \mathrm{p}$.

[8] U.S. Department of Education, Office of Communications and Outreach. Helping Your Child Learn Mathematics, Washington, D.C., 2005. $-43 \mathrm{p}$.

[9] Sayfullaev, N. Current Issues on Fine ARTS Education: Continuity and Prospects for Development. Religación, 4, 192194.

[10] Omonov, Q., \& Karimov, N. (2020). Importance Of Ancestoral Heritage. The American Journal of Social Science and Education Innovations, 2(09), 196-202. 